Resarech Paper:

\title{
The Effect of a Family-centered Empowerment Model on the Quality of Life of Patients With Stroke
}

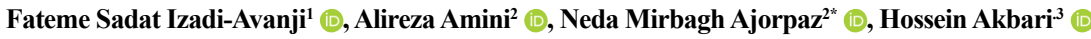 \\ 1. Trauma Nursing Research Center, Faculty of Nursing and Midwifery, Kashan University of Medical Sciences, Kashan, Iran. \\ 2. Autoimmune Diseases Research Center, Faculty of Nursing and Midwifery, Kashan University of Medical Sciences, Kashan, Iran. \\ 3. Department of Health, Safety, and Environment Management, Faculty of Health, Kashan University of Medical Sciences, Kashan, Iran
}

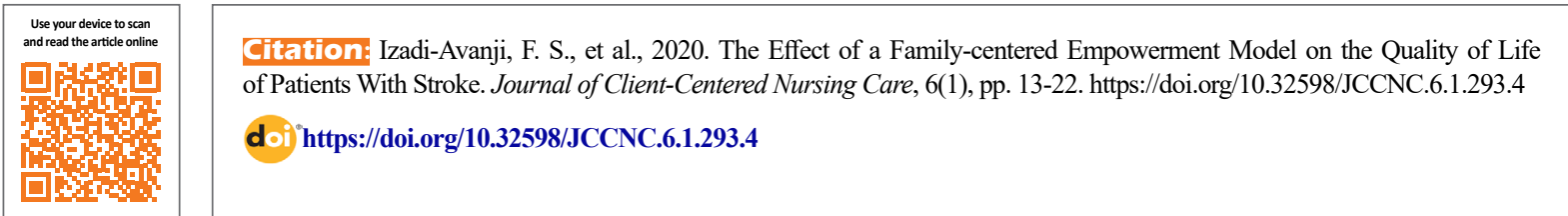

\section{(c) (i) (s)}

Article info:

Received: 17 Jul 2019

Accepted: 13 Nov 2019

Published: 01 Feb 2020

Keywords:

Stroke, Empowerment, Family-centered model, Quality of Life

\begin{abstract}
A B S T RA C T
Background: Stroke upsets the quality of life of the patients and their families. The participation of the family in caring for these patients is inevitable. Empowerment programs enhance patients' motivation and knowledge and improve their quality of life and self-care. This research aimed to determine the effect of a program based on the family-centered empowerment model on the quality of life of patients with stroke.
\end{abstract}

Methods: This clinical trial study was performed on 100 patients with stroke in Shahid Beheshti Hospital in Kashan City, Iran. The subjects were first recruited purposefully and then were randomly divided into two groups. The experimental group received a family-centered empowerment training in 8 sessions, while the control group received no intervention. The patients in the two groups completed the stroke-specific quality of life scale before the intervention, immediately after the intervention, and one and two months after the last training session. The obtained data were analyzed using the Chi-square test, repeated measures ANOVA, and t-test in SPSS V. 19.

Results: Comparison of the experimental and control groups showed that the total score of quality of life significantly changed immediately after the intervention, and one and two months later $(\mathrm{P}<0.05)$. Repeated measures ANOVA results reported a significant interaction between time and group in the total quality of life score and some of its dimensions (energy, family role, social role, language, mobility, self-care, upper extremity function, and work/productivity) $(\mathrm{P} \leq 0.05)$.

Conclusion: This model of empowerment can improve the quality of life of patients with stroke. This model is recommended to use in the educational program of these patients.

\footnotetext{
* Corresponding Author:

Neda Mirbagh Ajorpaz, PhD.

Address: Autoimmune Diseases Research Center, Faculty of Nursing and Midwifery, Kashan University of Medical Sciences, Kashan, Iran Tel: +98 (913) 2130397

E-mail:salam_20012003@yahoo.co.uk
} 


\section{Highlights}

- Stroke is one of the leading causes of death and disability in the world.

- Stroke survivors may face new challenges such as living with their disabilities.

- The family-centered empowerment model can increase the quality of life in patients with stroke.

\section{Plain Language Summary}

Stroke has a direct impact on health systems, resulting in high costs. It is also a global public health problem due to multiple disabilities resulting from it. The family-centered empowerment model helps patients and their family members to collaboratively participate in an empowerment program and promote the patient's health. The results indicate that this model improved the quality of life of patients with stroke.

\section{Introduction}

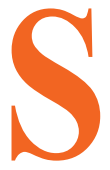

troke is a cerebrovascular disease in which the brain receives insufficient oxygen, leading to ischemia and then death. Stroke is the second leading cause of death in the world (Marshall et al., 2015). Fifteen million people worldwide suffer from a stroke each year. Of these, 5 million people die and 5 million people become disabled (Addo et al., 2012). Most deaths from stroke occur in countries with low economic level (Marshall et al., 2015). In Iran, one of the most common diseases is ischemic heart disease and stroke. Each year, 139 per 100000 people are affected by stroke in Iran (Talebi et al., 2020). The most common causes of stroke are high blood pressure, diabetes, and alcohol abuse (Cantu-Brito et al., 2010). Stroke has a direct impact on health systems, resulting in high costs, serious disabilities, functional limitations, and compromised Quality of Life (QoL) (Baumann et al., 2014). The impact of stroke on people's lives is an important concern for society. Stroke affects both the individual and the family, who are generally unprepared to cope with the rehabilitation process or disability caused by the condition. As a result, many people are unable to work and do not get paid after stroke (Panício et al., 2014; Baumann et al., 2014).

Survivors of stroke face a new challenge, namely living with disabilities. Patients with physical and or psychological consequences need special rehabilitation to achieve functional improvement. Besides, the integration of communication between the family and society is crucial for improving the patient's QoL (Liao 2020). Studies conducted on stroke patients have demonstrated that stroke affects various domains of life, including functionality (Khalid et al., 2016; Kristinsson \& Halldorsdot- tir 2020). Therefore, one of the main goals of treatment in these patients is to reduce disabilities and increase their QoL (Rafii, Haghani \& Heidari Beni 2017). Health care providers can reduce the complications of the disease by performing effective interventions. As a result, they can improve the QoL of these patients (Haley et al., 2015). Among the members of the health care system, nurses have the most frequent contact with the patients and their companions. They can use appropriate methods to increase the QoL in these patients (Caro et al., 2018). Researchers in the field of health promotion believe that the role of the family is essential in the care and treatment of the disease (Qiu, Sit \& Koo 2018; Park et al., 2018).

Cooperation between the nurse and the patient's family to solve the patient's problems is one of the crucial goals of the empowerment model (Addo et al., 2012). Empowerment enables people to take advantage of their abilities, capacities, and talents. Many researchers believe that empowerment is an active, dynamic, and interactive approach. It is a method that is formed in relation to others to respond better to treatment, prevent complications, reduce health care costs, and create a positive view toward the disease (Haley et al., 2015). Empowering the family means helping the patient's family to change their behaviors (Caro et al., 2018). The main aim of the family-centered model is to increase the patient and family knowledge for health promotion (Vallury, Jones \& Gray 2015). Some studies have been conducted with this approach on the QoL of older adults (Masoudi et al., 2010), patients with thalassemia (Borhani et al., 2011), and asthma (Teymori, Alhani \& Kazemnezhad 2011) to examine the effects of the empowerment model. The family-centered empowerment model is a native model with the centrality of the family. The model was first designed by Alhani et al. (2013) for chronic patients in Iran. This model has not been used, so far, for stroke patients. 
The family-centered empowerment model motivates the patients and their families and increases their efficiency, self-esteem, and self-control. Attitude, knowledge, and perceived threat are domains of the model Alhani et al. (2013). Studies have shown that empowerment models are practical and associated with improvement and modification of QoL (Caro et al., 2018; Borhani et al., 2011: Teymori, Alhani \& Kazemnezhad 2011). Community health nurses as the members of interdisciplinary teams play an important role in the prevention and management of chronic diseases (Liao et al., 2020). It should be noted that severe complications could occur due to inappropriate care and treatment. No study has been done about the use of this model in stroke patients. Therefore, this study aimed to determine the effect of a family-centered empowerment model on the QoL in stroke patients.

\section{Materials and Methods}

\section{Design and sample}

This research was a clinical trial and the setting was Shahid Beheshti Hospital of Kashan, Iran. The sample size was estimated 50 based on the Pocock formula (Pocock 1983). According to Vahedian-Azimi (2015), d (subtracting two means from each other) was equal to 28.3 , and $\partial$ (standard deviation) was equal to 54.8. The study power was 0.80 and type I error probability of 0.05 . The patients were randomly divided into the experimental $(n=50)$ and control ( $\mathrm{n}=50)$ groups (www.random.org).

The inclusion criteria for the patients were diagnosis of stroke, no perceptual-cognitive deficits (Mini-Mental Status Examination [MMSE] >24), with at least one complication of stroke such as motion disorder, speech disorder, swallowing disorder, etc. The exclusion criteria for the patients were lack of participating in more than one session and unwillingness to complete the research tools. The inclusion criteria for the active member of the family were being a constant participating member in the study such as a spouse or a child who lives with the patient in the family, having the ability to make a decision, showing interest in participating in the research (with the understanding of the importance of the patient' health). The exclusion criteria for an active member were unwillingness to participate and continuing cooperation in the research at any stage.

Initially, the first researcher searched the hospital's medical files and checked the documents of patients with stroke. A total of 122 patients were selected by a convenient sampling method; of them, 22 patients were ex- cluded (12 patients did not meet the inclusion criteria and 10 patients declined to participate in the study) (Figure 1). Then, 100 patients were recruited purposively. After presenting the necessary explanations, the study purpose, and obtaining informed consent, patients were randomly divided into control and experimental groups. To control confounding factors and prevent data contamination, first, the control group was recruited. The groups were matched in terms of medications and treatment type.

\section{Study instruments}

The obtained data were collected by Stroke-Specific Quality Of Life (SSQOL) scale and a demographic questionnaire comprising age, sex, education, marital status, number of children, the caregiver's relationship with the patient, and other diseases. The SSQOL scale has 49 questions in 12 dimensions of life quality. These dimensions include family roles (3 items), energy (3 items), mobility (6 items), language ( 5 items), personality ( 3 items), mood (5 items), reasoning (3 items), self-care (5 items), upper extremity function ( 5 items), work/productivity (3 items), social roles (5 items) and vision (3 items). This questionnaire is rated on a 5-point Likert-type from completely agree (1) to completely disagree (5). Its total score is between 49 and 249. Scores between 49 and 123 indicate low quality of life, and scores between 124 and 249 indicate good quality of life (Williams et al., 1999). Odetunde, Akinpelu \& Odole (2017) recognized the reliability of SSQOL. In Iran, Ganvir, Harishch \& Kunde (2018) confirmed the reliability of this scale. The Cronbach alpha coefficient of the questionnaire in this study was 89\%. The Mini-Mental Status Examination (MMSE) was used to screen dementia in this study. It has 11 questions to evaluate registration, orientation, recall, attention, comprehension (verbal and written), and calculation (serial sevens or spelling), naming, writing, repetition, and construction. Its cut-off point is less than 24 and its maximum score is 30 . The higher the score represents better performance (Foroughan et al., 2008). The Cronbach alpha was calculated $90 \%$ in this research.

The mental status score of all the research participants was estimated using the MMSE questionnaire. Based on this scale, the patients were selected in the case of obtaining MMSE >24 (Foroughan et al., 2008).

\section{Study procedure}

The patients in the experimental group were placed into five groups of 10 people each. All groups participated in 8 empowerment sessions (twice a week, for four weeks, each session 40-60 min) based on the family-cen- 
tered empowerment model. The sessions were held with the presence of the researchers, patients, and the active members of their family. The family-centered empowerment model was performed according to the steps in the following order.

According to the model, the first session was about collecting the threat perception through enriching the knowledge about the stroke. Also, educational booklets about stroke and its care were given to patients and the active members of their families. The sessions were held according to needs assessment. The next part was problem-solving to increase self-confidence, self-efficacy, and adapting to the problem. In the third part of the previous training were given a $\mathrm{CD}$ to the patient and her/ his family and they were encouraged to participate in the care. Homework was given from the educational materials of the same session, for example, recording problems and complications of the disease on a daily basis. At the beginning of the next session, the homework was checked and feedback was given by the first researcher. The first researcher would call the patient once a week to make sure the program was running properly and answer their questions (Table 3).

The subjects in the control group received usual care and educations. At the end of the study, they received educational pamphlets. SSQOL scale was completed by the groups before, at the end of the intervention, one month, and two months later.

Completing the questionnaire in the next two months after the intervention became possible by phone calls and asking the patients and their families to attend the hospital in a specific time to check the complications of the disease and the effectiveness of the intervention.

\section{Data analysis}

The study information was analyzed in SPSS V. 19 (SPSS Inc., Chicago, IL, USA). A Chi-squared test was applied for analyzing qualitative variables. The paired t-test and independent samples t-test were used for assessing the QoL. For comparing the mean score of the groups' QoL before and after the intervention, as well as one month and two months later, we used the repeated measures ANOVA. In all statistical tests, the significant level was set at 0.05 or less.

\section{Results}

During the study, two members of the experimental group dropped. The reason was the absence of more than two sessions from the training. Finally, the information of 96 participants was analyzed (Figure 1).

The Mean $\pm \mathrm{SD}$ age of the experimental group was $66.1 \pm 6.5$ and that of the control group was $66.4 \pm 6.7$ years. Two groups lacked a significant difference in demographic data (Table 1). The results of the independent t-test also indicated no significant difference between the experimental and control groups at the beginning of the study regarding the total scores of QoL $(\mathrm{P}>0.05)$. In the experimental group, the results of the ANOVA test showed that the mean QoL score and its dimensions (energy, family role, social role, language, mobility, upper extremity function, self-care, and work/productivity) increased across the four measurement time points $(\mathrm{P} \leq 0.05)$.

ANOVA test revealed a significant interaction between time $\times$ group on the total score of life quality and some of its dimensions (upper extremity function, energy, selfcare, family role, mobility, social role, language, and work/productivity) $(\mathrm{P} \leq 0.05)$ (Table 2$)$.

\section{Discussion}

The results indicated that the difference between the mean score of total QoL of the experimental and control groups was significant immediately after the intervention, and also one and two months later. This means that the empowerment model had positive effects on the QoL of the patients with stroke. Deyhoul et al. (2019) reported that the family-centered model had a positive and significant effect on the QoL and daily activities of stroke patients. It also reduced the workload of their caregivers. In this study, follow up was done two months after the intervention (Deyhoul et al., 2019). Other studies have also shown that the family-centered empowerment model is effective in rehabilitation and self-care of patients with stroke (Creasy et al., 2015). The results of these research studies are consistent with the present research results. It is believed that empowering patients about the disease and its control is very important and effective in controlling the disease.

Some studies have also shown that educating patients with stroke allows them to pay more attention to their disorders and to be more responsive to the control and management of the illness (Eghlidi et al., 2016; Gholizadeh et al., 2015). Eames et al. (2013) examined the effects of an educational package, including psychological and physical training on the QoL in patients with stroke and their family members. Contrary to the current research, the results of their research acknowledged no statistically significant difference between the quality of life in the 
Table 1. Demographic data in two groups

\begin{tabular}{|c|c|c|c|c|}
\hline & & Mea & & \\
\hline Var & ble & & & $\mathbf{P}$ \\
\hline & & Experimental & Control & \\
\hline $\mathrm{Ag}$ & & $66.1 \pm 6.5$ & $66.4 \pm 6.7$ & 0.23 \\
\hline Number & children & $4.4 \pm 1.20$ & $4.8 \pm 1.6$ & 0.52 \\
\hline & Female & $14(29.1)$ & $20(41.7)$ & \\
\hline Sex & Male & 34 (70.9) & $28(58.3)$ & 0.97 \\
\hline Education & Elementary & $41(85.4)$ & $44(91.6)$ & 0.77 \\
\hline & Higher than elementary & $7(14.6)$ & $4(8.4)$ & \\
\hline Marital totus & Single & $11(22.02)$ & $21(43.75)$ & 25 05 \\
\hline 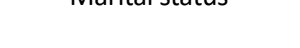 & Married & $37(77.08)$ & $27(56.25)$ & \\
\hline & Child & $25(52.08)$ & $26(54.16)$ & \\
\hline $\begin{array}{l}\text { The caregiver's relation- } \\
\text { ship with the patient }\end{array}$ & Spouse & $13(27.08)$ & $11(22.92)$ & 0.59 \\
\hline & Other & $10(20.84)$ & $11(22.92)$ & \\
\hline Ot. & Yes & $43(89.58)$ & $45(93.75)$ & r \\
\hline GLter UIseases & No & $5(10.42)$ & $3(6.25)$ & كב.0 \\
\hline
\end{tabular}

Table 2. Comparing the quality of life scores according to timexgroup interaction

\begin{tabular}{|c|c|c|c|c|c|c|c|c|}
\hline \multirow{2}{*}{$\begin{array}{c}\text { Quality of } \\
\text { Life }\end{array}$} & \multirow{2}{*}{ Group } & $\begin{array}{l}\text { Before the } \\
\text { Intervention }\end{array}$ & $\begin{array}{c}\text { At the end of } \\
\text { the Interven- } \\
\text { tion }\end{array}$ & \multirow[t]{2}{*}{$\begin{array}{l}\text { One Month } \\
\text { After the } \\
\text { Intervention }\end{array}$} & \multirow[t]{2}{*}{$\begin{array}{l}\text { Two Months } \\
\text { After the } \\
\text { Intervention }\end{array}$} & \multicolumn{3}{|c|}{$\begin{array}{c}\text { Repeated Measures } \\
\text { ANOVA* } \\
\text { P }\end{array}$} \\
\hline & & \multicolumn{2}{|c|}{ Mean \pm SD } & & & Time & $\begin{array}{l}\text { Time } \times \\
\text { Group }\end{array}$ & Group \\
\hline \multirow{3}{*}{ Energy } & Experimental & $6.1 \pm 2.1$ & $7.16 \pm 2.7$ & $7.98 \pm 2.2$ & $9.46 \pm 2.8$ & & & \\
\hline & Control & $5.88 \pm 2.5$ & $6.58 \pm 2.1$ & $6.17 \pm 1.3$ & $7.65 \pm 2.8$ & & $<0.001$ & \\
\hline & $\mathrm{P} * *$ & 0.51 & 0.01 & 0.01 & 0.001 & & & \\
\hline \multirow{3}{*}{ Family roles } & Experimental & $5.1 \pm 1.1$ & $6.26 \pm 2.1$ & $7.49 \pm 2.2$ & $8.46 \pm 2.8$ & & & \\
\hline & Control & $5.80 \pm 1.2$ & $5.65 \pm 2.8$ & $6.27 \pm 1.9$ & $6.82 \pm 2.3$ & & $<0.001$ & \\
\hline & $\mathrm{P} * *$ & 0.30 & 0.01 & 0.01 & 0.02 & & & \\
\hline \multirow{3}{*}{ Language } & Experimental & $15.25 \pm 2.2$ & $16.00 \pm 2.6$ & $17.55 \pm 2.1$ & $17.99 \pm 2.2$ & & & \\
\hline & Control & $15.00 \pm 2.6$ & $15.55 \pm 1.5$ & $16.89 \pm 2.8$ & $17.15 \pm 2.3$ & & $<0.001$ & \\
\hline & $\mathrm{P} * *$ & 0.25 & 0.04 & 0.01 & 0.01 & & & \\
\hline \multirow{3}{*}{ Mobility } & Experimental & $16.15 \pm 2.4$ & $17.43 \pm 1.8$ & $17.87 \pm 2.1$ & $18.00 \pm 2.2$ & & & \\
\hline & Control & $16.21 \pm 2.1$ & $16.54 \pm 2.1$ & $17.11 \pm 2.00$ & $17.21 \pm 2.6$ & & $<0.001$ & \\
\hline & $\mathrm{P} * *$ & 0.44 & 0.01 & 0.02 & 0.001 & & & \\
\hline \multirow{3}{*}{ Mood } & Experimental & $13.22 \pm 2.3$ & $13.42 \pm 2.6$ & $13.54 \pm 2.7$ & $13.57 \pm 2.1$ & & & \\
\hline & Control & $13.52 \pm 2.6$ & $13.45 \pm 1.7$ & $12.65 \pm 1.7$ & $12.42 \pm 2.3$ & & $>0.05$ & \\
\hline & P value** & 0.25 & 0.21 & 0.22 & 0.23 & & & \\
\hline \multirow{3}{*}{ Personality } & Experimental & $7.23 \pm 2.5$ & $7.88 \pm 2.8$ & $8.48 \pm 2.1$ & $8.76 \pm 2.6$ & & & \\
\hline & Control & $7.88 \pm 2.3$ & $17.99 \pm 2.2$ & $8.48 \pm 2.1$ & $8.76 \pm 2.1$ & & $>0.05$ & \\
\hline & $\mathrm{P} * *$ & 0.21 & 0.16 & 0.42 & 0.51 & & & \\
\hline
\end{tabular}




\begin{tabular}{|c|c|c|c|c|c|c|c|c|}
\hline \multirow{2}{*}{$\begin{array}{l}\text { Quality of } \\
\text { Life }\end{array}$} & \multirow{2}{*}{ Group } & $\begin{array}{l}\text { Before the } \\
\text { Intervention }\end{array}$ & $\begin{array}{l}\text { At the end of } \\
\text { the Interven- } \\
\text { tion }\end{array}$ & \multirow[t]{2}{*}{$\begin{array}{l}\text { One Month } \\
\text { After the } \\
\text { Intervention }\end{array}$} & \multirow[t]{2}{*}{$\begin{array}{l}\text { Two Months } \\
\text { After the } \\
\text { Intervention }\end{array}$} & \multicolumn{3}{|c|}{$\begin{array}{c}\text { Repeated Measures } \\
\text { ANOVA* } \\
\text { P }\end{array}$} \\
\hline & & \multicolumn{2}{|c|}{ Mean士SD } & & & Time & $\begin{array}{l}\text { Time } x \\
\text { Group }\end{array}$ & Group \\
\hline \multirow{3}{*}{ Self-care } & Experimental & $16.13 \pm 2.4$ & $17.14 \pm 2.9$ & $17.99 \pm 1.8$ & $18.24 \pm 2.8$ & & & \\
\hline & Control & $16.74 \pm 2.1$ & $16.85 \pm 2.1$ & $17.04 \pm 2.6$ & $17.24 \pm 2.4$ & & $<0.001$ & \\
\hline & $\mathrm{P} * *$ & 0.14 & 0.04 & 0.04 & 0.03 & & & \\
\hline \multirow{3}{*}{ Social roles } & Experimental & $10.94 \pm 2.5$ & $12.12 \pm 2.6$ & $13.18 \pm 2.2$ & $13.98 \pm 2.9$ & & & \\
\hline & Control & $11.10 \pm 3.9$ & $11.35 \pm 2.3$ & $12.14 \pm 1.8$ & $12.43 \pm 2.4$ & & $<0.001$ & \\
\hline & $\mathrm{P}^{* *}$ & 0.35 & 0.01 & 0.01 & 0.01 & & & \\
\hline \multirow{3}{*}{ Reasoning } & Experimental & $7.13 \pm 2.5$ & $8.21 \pm 22$ & $8.55 \pm 3.2$ & $8.57 \pm 3.5$ & & & \\
\hline & Control & $7.28 \pm 2.1$ & $8.11 \pm 2.5$ & $8.25 \pm 2.9$ & $8.43 \pm 2.7$ & & $>0.05$ & \\
\hline & $\mathrm{P}^{* *}$ & 0.16 & 0.10 & 0.35 & 0.13 & & & \\
\hline \multirow{3}{*}{$\begin{array}{l}\text { Upper } \\
\text { extremity } \\
\text { function }\end{array}$} & Experimental & $15.54 \pm 2.1$ & $16.30 \pm 1.9$ & $16.75 \pm 2.3$ & $17.19 \pm 2.7$ & & & \\
\hline & Control & $15.65 \pm 2.5$ & $15.84 \pm 2.6$ & $15.98 \pm 2.9$ & $16.14 \pm 2.1$ & & $<0.001$ & \\
\hline & $\mathrm{P}^{* *}$ & 0.14 & 0.04 & 0.04 & 0.03 & & & \\
\hline \multirow{3}{*}{ Vision } & Experimental & $11.34 \pm 1.5$ & $11.14 \pm 2.6$ & $11.35 \pm 2.1$ & $11.44 \pm 2.3$ & & & \\
\hline & Control & $11.45 \pm 1.1$ & $11.84 \pm 1.5$ & $11.64 \pm 2.9$ & $11.57 \pm 2.2$ & & $>0.05$ & \\
\hline & $\mathrm{P}^{* *}$ & 0.10 & 0.51 & 0.38 & 0.22 & & & \\
\hline \multirow{3}{*}{ Work } & Experimental & $6.14 \pm 2.1$ & $6.84 \pm 2.8$ & $7.94 \pm 1.3$ & $8.11 \pm 1.2$ & & & \\
\hline & Control & $6.12 \pm 2.4$ & $6.23 \pm 2.1$ & $7.00 \pm 0.8$ & $7.35 \pm 1.1$ & & $<0.001$ & \\
\hline & $\mathrm{P}^{* *}$ & 0.32 & 0.02 & 0.01 & 0.01 & & & \\
\hline \multirow{3}{*}{$\begin{array}{l}\text { Total quality } \\
\text { of life score }\end{array}$} & Experimental & $150.54 \pm 22.8$ & $156.78 \pm 23.8$ & $158.5 \pm 23.5$ & $159.14 \pm 22.3$ & & & \\
\hline & Control & $149.53 \pm 26.8$ & $151.62 \pm 24.1$ & $152.35 \pm 23.2$ & $152.67 \pm 21.8$ & & $<0.001$ & \\
\hline & $\mathrm{P}^{* *}$ & 0.41 & 0.01 & 0.001 & 0.001 & & & \\
\hline
\end{tabular}

Table 3. Contents of family-centered empowerment model for patients with stroke

Model Structure Session
Perceived threat $\begin{array}{r}\text { Content } \\ \text { - Introducing the model, explaining the research objectives and effects of the program, the } \\ \text { number of sessions. }\end{array}$




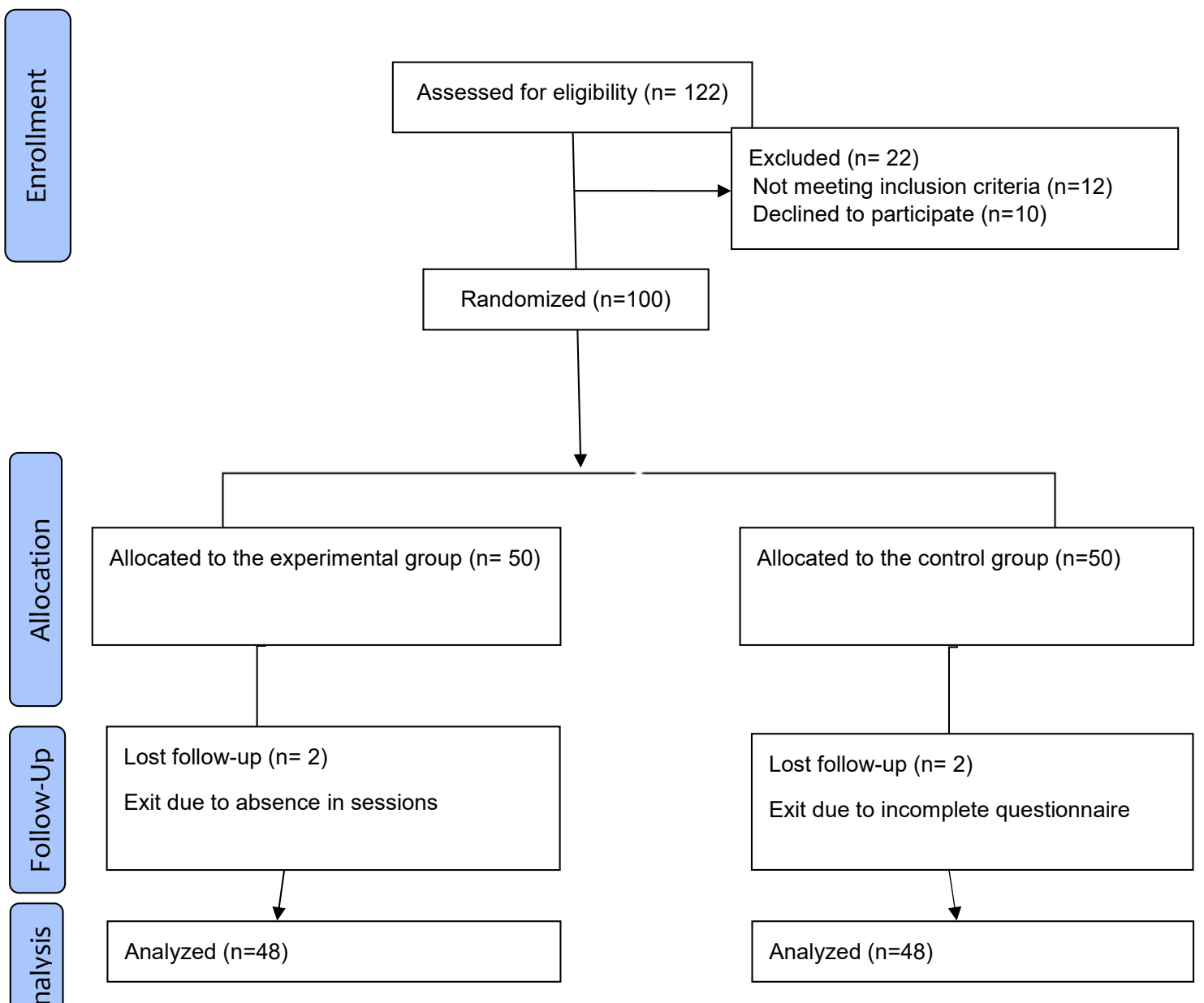

Figure 1. Sampling flow diagram

Client- Centered Nursing Care

experimental and control groups after training (Eames et al., 2013). Although their study was performed on stroke patients and their QoL, it differs from the present study in terms of the type of intervention and its evaluation. Also, the intervention was performed only on patients.

The results of our research also indicated a statistically significant difference between some of the subscales of life quality in the experimental group, including family roles, energy, upper extremity function, self-care, language, mobility, social roles, work, and productivity, immediately after the intervention, and then one and two months later. However, there was no significant difference between the domains of mood, personality, reasoning, and vision.

Unlike the present study, another study showed that energy and psychological subscales of QoL had the lowest and highest mean scores, respectively (Mazdeh \& Yaghobi 2009). The difference between this study and ours could be due to the implementation of empowerment sessions. In the present study, empowerment sessions were conducted in the presence of family members, while in the study of Mazdeh and colleagues, the sessions were held only with patients. Fens and colleagues showed that the empowerment of stroke patients based on the follow-up model had a significant positive effect on the production/work and social role subscales of the experimental group after the intervention and even 18 months later. However, there was no significant difference between QoL in the groups in their study (Fens et al., 2014). The results of their study in terms of work/ productivity and social role are consistent with the present study. However, in our study, the mean score of QoL increased significantly over time, but in the study of Fens et al., the mean score of QoL did not change significantly over time. It seems that the difference between their research and the present study could be related to the type of educational model. In our research, the family-based empowerment model was conducted while their study 
had used the follow-up empowerment model which was different in terms of content. The results of a study showed that the psychological and physical domains of the QoL of patients with stroke have increased significantly one year after the intervention, but social communication and mental health decreased, although this change was not significant (Chuluunbaatar, Chou \& Pu 2016). Similar to our study, in the study of Chuluunbaatar and colleagues, the physical subscales of quality of life increased significantly. Also, in their research, there were no significant differences between the elements of mental health such as mood, reasoning, and personality after the intervention.

Implementing a family-centered model improved the quality of life in stroke patients. Regarding the high incidence of stroke and its persistent disabilities, and considering that education and using of this model is a useful and financially viable method, this model is recommended for enhancing the QoL in patients with stroke.

\section{Ethical Considerations}

\section{Compliance with ethical guidelines}

All stages of the research were performed based on the Ethical Standards of the 1964 Helsinki Declaration and its subsequent recommendations. This research was approved by the Ethics Committee of Kashan University of Medical Sciences (No: 96227). This study was registered at the Iranian Registry of Clinical Trials (Code: IRCT20190617043915N1). All the study participants received explanations on the study procedure and its objectives and signed informed consent.

\section{Funding}

Financial support was provided by Kashan University of Medical Sciences.

\section{Authors' contributions}

Designing and obtaining fund for the study: Alireza Amini, Neda Mirbagher Ajorpaz, and Fatemeh Sadat Izadi-Avanji; Developing the analytical plan: Hossain Akbari; Preparing the final draft of the manuscript: Fatemeh Sadat Izadi-Avanji; Revising the manuscript and analyzing data: All authors.

\section{Conflict of interest}

The authors declared no conflict of interest.

\section{Acknowledgments}

The researchers appreciate the Research Deputy of Kashan University of Medical Sciences for financial support of the study.

\section{References}

Addo, J., et al., 2012. Socioeconomic status and stroke: An updated review. Stroke, 43(4), pp. 1186-91. [DOI:10.1161/ STROKEAHA.111.639732] [PMID]

Alhani, F., et al., 2003. [Empowerment of a family-oriented pattern and its effects on prevention of iron deficiency anemia in adolescent girls (Persian)]. Pejouhandeh, 8(4), pp. 283-9. https://www.sid.ir/En/Journal/ViewPaper.aspx?ID=5439

Baumann, M., et al., 2014. Associations between quality of life and socioeconomic factors, functional impairments and dissatisfaction with received information and homecare services among survivors living at home two years after stroke onset. BMC Neurology, 14, p. 92. [DOI:10.1186/1471-2377-14-92] [PMID] [PMCID]

Borhani, F., et al., 2011. The effect of family-centered empowerment model on quality of life of school-aged children with thalassemia major. Iranian Journal of Nursing and Midwifery Research, 16(4), pp. 292-8. [PMID] [PMCID]

Cantu-Brito, C., et al., 2010. Hospitalized stroke surveillance in the community of Durango, Mexico: The brain attack surveillance in Durango study. Stroke, 41(5), pp. 878-84. [DOI:10.1161/STROKEAHA.109.577726] [PMID]

Caro, C. C., et al., 2018. Burden and quality of life of family caregivers of stroke patients. Occupational Therapy in Health Care, 32(2), pp. 154-71. [DOI:10.1080/07380577.2018.1449046] [PMID]

Chuluunbaatar, E., Chou, Y. J. \& Pu, C. 2016. Quality of life of stroke survivors and their informal caregivers: A prospective study. Disability and Health Journal, 9(2), pp. 306-12. [DOI:10.1016/j.dhjo.2015.10.007] [PMID]

Creasy, K. R., et al. 2015. Clinical implications of family-centered care in stroke rehabilitation. Rehabilitation Nursing, 40(6), pp. 349-59. [DOI:10.1002/rnj.188] [PMID] [PMCID]

Deyhoul, N., et al., 2019. The effect of family-centered empowerment program on the family caregiver burden and the activities of daily living of Iranian patients with stroke: A randomized controlled trial study. Aging Clinical and Experimental Research, 32(7), pp. 1343-52. [DOI:10.1007/s40520-019-01321-4] [PMID]

Eames, S., et al., 2013. Randomised controlled trial of an education and support package for stroke patients and their carers. BMJ Open, 3(5), p. e002538. [DOI:10.1136/bmjopen-2012-002538] [PMID] [PMCID]

Eghlidi, J., et al., 2016. [Effects of mental practices on balance and quality of life in stroke (Persian)]. Scientific Journal of Rehabilitation Medicine, 4(4), PP. 20-7. [DOI:10.22037/JRM.2015.1100218] 
Fens, M., et al., 2014. Effect of a stroke-specific follow-up care model on the quality of life of stroke patients and caregivers: A controlled trial. Journal of Rehabilitation Medicine, 46(1), pp. 7-15. [DOI:10.2340/16501977-1239] [PMID]

Foroughan, M., et al., 2008. Validation of Mini- Mental State Examination (MMSE) in the elderly population of Tehran. Advances in Cognitive Sciences, 10(2), pp. 29-37. https:/ / www.sid. ir/En/Journal/ViewPaper.aspx?ID=147028

Ganvir, S., Harishch, M. \& Kunde, C., 2018. Validation of Marathi version of stroke-specific quality of life. Annals of Indian Academy of Neurology, 21(4), pp. 290-3. [DOI: 10.4103/aian. AIAN_449_17] [PMID] [PMCID]

Gholizadeh, M., et al., 2015. [An evaluation on the effectiveness of patient care education on quality of life of stroke caregivers: A randomized field trial (Persian)]. Sabzevar University of Medical Sciences, 22(6), pp. 955-64. https://www.sid.ir/en/ journal $/$ ViewPaper.aspx?id=508565

Haley, W, E., et al., 2015. Long-term impact of stroke on family caregiver well-being: A population-based case-control study. Neurology, 84(13), pp. 1323-9. [DOI:10.1212/ WNL.0000000000001418] [PMID] [PMCID]

Khalid, W., et al., 2016. Quality of life after stroke in Pakistan. BMC Neurology, 16(1), p. 250. [DOI:10.1186/s12883-016-07741] [PMID] [PMCID]

Kristinsson, S. \& Halldorsdottir, T. H., 2020. Translation, adaptation and psychometric properties of the Icelandic stroke and aphasia quality of life scale-39g. Scandinavian Journal of Caring Sciences. Online Ahead of Print. [DOI:10.1111/scs.12840] [PMID]

Liao, X. L., 2020. The occurrence and longitudinal changes of cognitive impairment after acute ischemic stroke. Neuropsychiatric Disease and Treatment, 16, pp. 807-14. [DOI:10.2147/NDT. S234544] [PMID] [PMCID]

Marshall, I. J., et al., 2015. The effects of socioeconomic status on stroke risk and outcomes. The Lancet Neurology, 14(12), pp. 1206-18. [DOI:10.1016/S1474-4422(15)00200-8] [PMID]

Masoudi, R., et al., 2010. [The effect of family centered empowerment model on the quality of life in elderly people (Persian)] The Journal of Qazvin University of Medical Sciences, 14(1), pp. 57-64. http://journal.qums.ac.ir/article-1-930-en.html

Mazdeh, M. \& Yaghobi, A., 2009. [The Study of quality of life in aphasic stroke patients in University- Medical Centers of Hamedan (Persian)]. Qom University of Medical Sciences Journal, 3(1), pp. 21-8. http://journal.muq.ac.ir/article-1-36-en.html

Odetunde, M. O., Akinpelu, A. O, \& Odole, A. C., 2017. Validity and reliability of a Nigerian-Yoruba version of the strokespecific quality of life scale 2.0. Health and Quality of Life Outcomes, 15(1), p. 205. [DOI:10.1186/s12955-017-0775-9] [PMID] [PMCID]

Panício, M. I., et al., 2014. The influence of patient's knowledge about stroke in Brazil: A cross sectional study. Arq Neuropsiquiatr, 72(12), pp. 938-41. [DOI:10.1590/0004-282X20140167] [PMID]

Park, M., et al., 2018. Patient- and family-centered care interventions for improving the quality of health care: A review of systematic reviews. The International Journal of Nursing Studies, 87, pp. 69-83. [DOI:10.1016/j.ijnurstu.2018.07.006] [PMID]
Pocock, S. J., 1983. Clinical trials: A practical approach. Hoboken: John Wiley \& Sons. https://books.google.com/ books?id=Oj5rAAAAMAAJ\&dq

Qiu, X., Sit J. W. H., \& Koo, F. K., 2018. The influence of Chinese culture on family caregivers of stroke survivors: A qualitative study. Journal of Clinical Nursing, 27(1-2), pp. e309-19. [DOI:10.1111/jocn.13947] [PMID]

Rafii, F., Haghani, H., \& Heidari Beni, F., 2017. Health-related quality of life and related factors in patients with chronic obstructive pulmonary disease. Journal of Client-centered Nursing Care, 3(1), pp. 45-50. [DOI:10.32598/jccnc.3.1.45]

Talebi, A., et al., 2020. Cerebrovascular disease: How serum phosphorus, vitamin $\mathrm{D}$, and uric acid levels contribute to the ischemic stroke. BMC Neurology, 20(1), pp. 116. [DOI:10.1186/ s12883-020-01686-4] [PMID] [PMCID]

Teymori, F., Alhani, F., \& Kazemnezhad, A., 2011. The effect of family-centered empowerment model on the quality of life of school-age asthma children. Iranian Journal of Nursing Research, 6(20), pp. 52-63. http://ijnr.ir/article-1-801-en.html

Vahedian-azimi, A., et al., 2015. [Effect of family-centered empowerment model on the quality of life in patients with myocardial infarction: A clinical trial study (Persian)]. Journal of Nursing Education, 4(1), PP. 8-22. http://jne.ir/article1-440-en.html

Vallury, K. D. B., Jones M., \& Gray R., 2015. Do family-oriented interventions reduce post stroke depression? A systematic review and recommendations for practice. Topics in Stroke Rehabilitation, 22(6), pp. 453-9. [DOI:10.1179/107493571 5Z.00000000061] [PMID]

Williams, L. S., et al., 1999. Development of a stroke-specific quality of life scale. Stroke, 30(7), pp. 1362-9. [DOI:10.1161/01. STR.30.7.1362] [PMID] 
This Page Intentionally Left Blank 